\title{
Multi-species regime shifts reflected in spawning temperature optima of small pelagic fish in the western North Pacific
}

\author{
Akinori Takasuka*, Yoshioki Oozeki, Hiroshi Kubota \\ National Research Institute of Fisheries Science, Fisheries Research Agency, 2-12-4 Fukuura, Kanazawa, \\ Yokohama, Kanagawa 236-8648, Japan
}

\begin{abstract}
Small pelagic fish have exhibited cyclic population dynamics in complex marine ecosystems worldwide. These fish regime shifts have been associated with ocean regime shifts; however, the biological mechanisms have remained unresolved and have been considered to depend mainly on multi-step processes through food webs. In the present study, we focus on species-specific temperature optima and show that similarities and differences in spawning temperature optima reflect those in the long-term population dynamics among multi-species pelagic fish in the western North Pacific. Spawning temperature optima were examined for anchovy, sardine, mackerel and jack mackerel, based on the occurrence of eggs and larvae, using a long-term (1978 to 2004) data set of egg and larval surveys off the Pacific coast of Japan. Anchovy exhibited a plateau-like spawning temperature pattern with a peak at ca. $22^{\circ} \mathrm{C}$. In contrast, sardine and mackerel exhibited steeply peaked patterns with marked peaks at ca. 16 and $18^{\circ} \mathrm{C}$, respectively. On the contrary, jack mackerel showed a very similar spawning temperature pattern to anchovy. These relationships were consistent with their flourish and collapse in long-term population dynamics. Furthermore, sardine and mackerel with stenothermal spawning patterns showed dramatic fluctuations relative to anchovy and jack mackerel with more eurythermal features. The multi-species comparisons extracted a simple and direct pathway: if viewed at large scales, direct temperature impacts on vital parameters provide a plausible explanation of multi-species regime shifts of small pelagic fish in the western North Pacific.
\end{abstract}

KEY WORDS: Fish regime shift · Spawning temperature optimum $\cdot$ Long-term population dynamics Anchovy $\cdot$ Sardine $\cdot$ Mackerel $\cdot$ Jack mackerel $\cdot$ Western North Pacific

Resale or republication not permitted without written consent of the publisher

\section{INTRODUCTION}

Marine ecosystems are complex. Over broad time scales, small pelagic fish have exhibited cyclic population dynamics worldwide. Different species tend to show in-phase or out-of-phase oscillations with one another. These large-scale 'fish regime shifts' have been associated with climate fluctuations and 'ocean regime shifts' rather than local or episodic events (McGowan et al. 1998, Attrill \& Power 2002, Chavez et al. 2003). However, the biological mechanisms underlying these fish regime shifts have remained unresolved.
In the western North Pacific, population dynamics of small pelagic fish appear to have responded to the Pacific Decadal Oscillation (PDO), a proxy for Pacific climate variability (Mantua et al. 1997, Mantua \& Hare 2002), at multi-decadal scales (Fig. 1). The landings have dramatically risen and fallen in response to the climate-induced ocean regime shifts, influencing fisheries. The mechanisms regulating fish population dynamics have long been discussed, focusing on trophic interactions and multi-step processes through food webs (Beaugrand et al. 2003, Platt et al. 2003, Frank et al. 2005, Ware \& Thomson 2005). Typically, these theories assume that physical state (e.g. temper- 

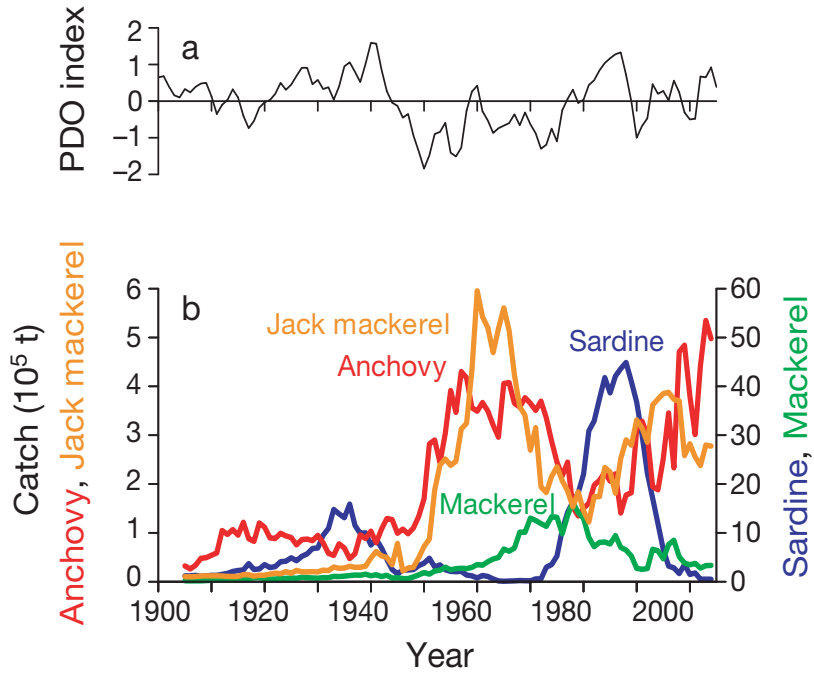

Fig. 1. Multi-species regime shifts of small pelagic fish in response to oceanographic changes in the western North Pacific. (a) Pacific Decadal Oscillation (PDO) index, which was defined as the leading principal component of monthly SST anomalies in the North Pacific, poleward of $20^{\circ} \mathrm{N}$ (the monthly mean global avg. SST anomalies were removed) (Mantua et al. 1997, Mantua \& Hare 2002). (b) Landing histories of anchovy Engraulis japonicus, sardine Sardinops melanostictus, mackerels Scomber japonicus and $S$. australasicus and jack mackerel Trachurus japonicus throughout Japan from 1905 to 2004. The landing data were updated from Yatsu et al. (2005) and were originally based on the data set from Statistics of Agriculture, Forestry and Fisheries

ature and upwelling) shifts alter primary production and zooplankton biomass, which then regulate pelagic fish recruitment through the food supply ('bottom-up' control). In turn, large fish predators, birds and mammals could influence pelagic fish populations through intensive predation pressure ('top-down' control). The prevailing scenarios could explain singlespecies dynamics but have failed to address multispecies phenomena. For example, why do some species flourish and others collapse simultaneously despite similar environmental conditions? In addition, why do taxonomically separate species exhibit inphase oscillations, while more related species exhibit out-of-phase oscillations?

In the present study we focus on species-specific temperature optima to extract a direct process linking climate fluctuations to multi-species regime shifts of small pelagic fish, using a long-term (1978 to 2004) data set of egg and larval surveys off the Pacific coast of Japan. Spawning temperature patterns were examined based on the occurrence of eggs and larvae compared with the long-term population dynamics recorded in landing histories for multi-species pelagic fish in the western North Pacific, in terms of similarities and differences among species.

\section{MATERIALS AND METHODS}

The long-term data set of the monthly egg and larval surveys, which have been historically conducted off the Pacific coast of Japan (Fig. 2) by the national fisheries research institute of the Fisheries Research Agency and 18 prefectural experimental stations, was organized and updated to examine the spawning temperatures of major commercial small pelagic fish in the western North Pacific: Japanese anchovy Engraulis japonicus, Japanese sardine Sardinops melanostictus, chub and spotted mackerel, Scomber japonicus and S. australasicus, and Japanese jack mackerel Trachurus japonicus. These species in all accounted for ca. 20 to $50 \%$ of annual total landings in weight of fish in Japan during the last half century. In the egg and larval surveys, a conical or cylindrical-conical plankton net with a diameter of 45 or $60 \mathrm{~cm}$ and a mesh size of 0.33 or $0.335 \mathrm{~mm}$ was vertically towed from $150 \mathrm{~m}$ depth or just above the bottom (if $<150 \mathrm{~m}$ ) to the surface. Concurrently, sea surface temperature (SST) was measured using a bucket and a thermometer or by a conductivity-temperature-depth profiler at each station. The survey areas and stations were organized to cover the major spawning grounds off the Pacific coast of Japan throughout the year in general (Fig. 2). The net samples were identified under a microscope and sorted for eggs and larvae of anchovy, sardine and mackerel, although only larvae were identified for jack mackerel. We adopted the most recent $27 \mathrm{yr}$ data set comprising the results of a total of 102905 planktonnet tows (samples) from 1978 to 2004, because over 3000 samples were available per year. The sampling efforts were rather consistent over the years: the total no. of samples per year ranged from 3188 to 4308 for the period of 1978 to 2004. The data set covers all seasons and months, although the efforts tended to be more intensive during winter to spring: the mean no. of samples per month was 456, 385 and 383 for February, March and April, respectively, and ranged from 253 to 317 for the remaining months. The intended period includes both high- and low-biomass phases of the target species (Fig. 1). Thus, the data set enables 'speciesspecific' spawning temperature optima to be estimated with a high degree of accuracy based on the spawning temperature patterns averaged over the long period.

Spawning temperature optima were determined based on the occurrence of eggs and larvae in relation to SST by the method of Lluch-Belda et al. (1991), which adopts a quotient analysis on presence/absence data. All available data $(\mathrm{n}=102905)$ were pooled and classified into SST intervals of $0.1^{\circ} \mathrm{C}$, regardless of any other attribute (i.e. area, station, year, season, sampling time, etc.). The samples in which eggs and larvae occurred ('positive' samples) were extracted for anchovy eggs ( $\mathrm{n}=$ 


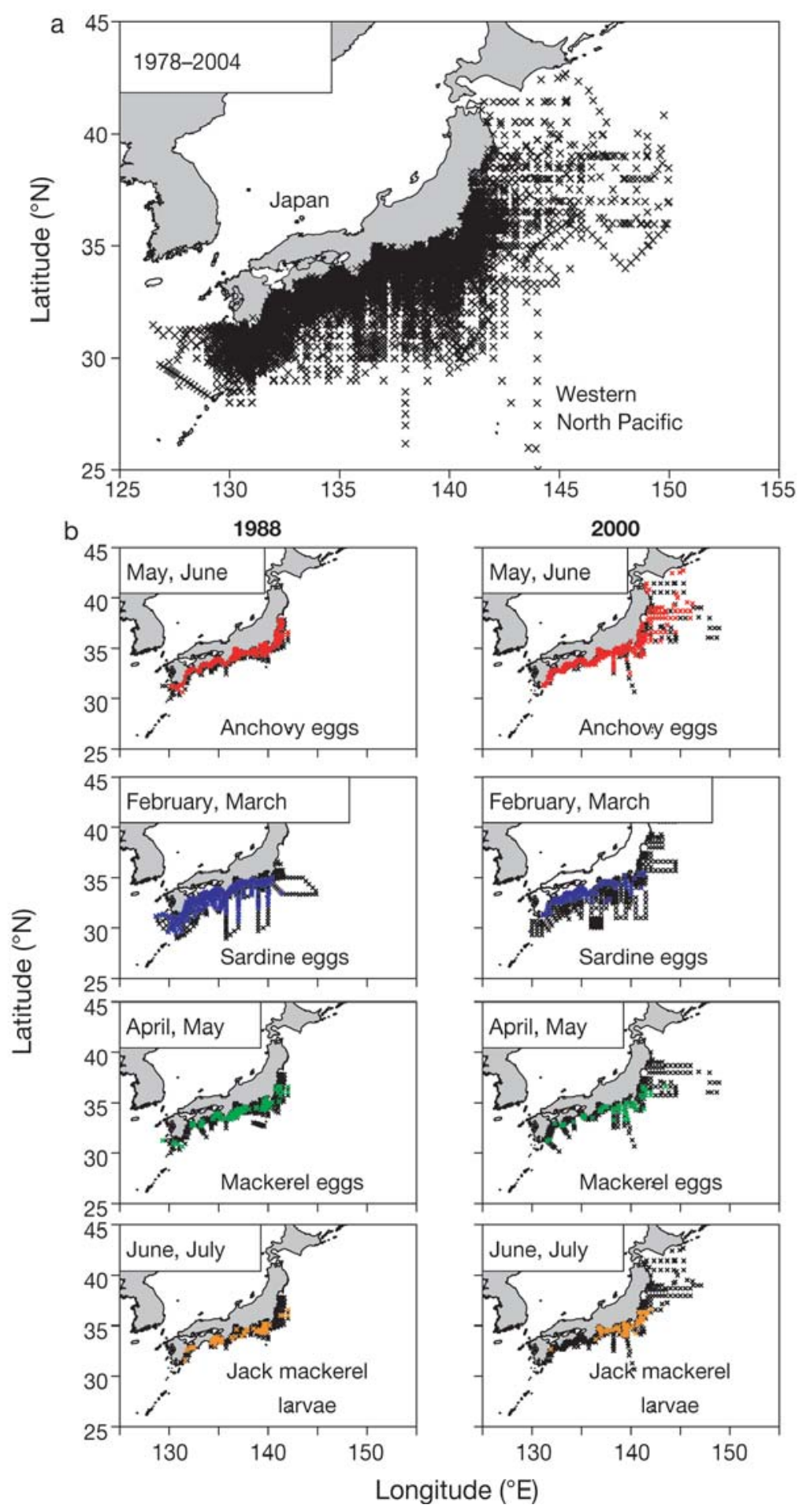

Fig. 2. Sampling stations of the egg and larval surveys off the Pacific coast of Japan. Both fixed and unfixed stations are collectively shown as crosses. (a) All sampling stations, at which 102905 plankton net tows were conducted in total from 1978 to 2004. (b) Examples of sampling stations and distributions of 'positive' stations (colored: stations at which eggs/larvae were collected) for anchovy Engraulis japonicus eggs, sardine Sardinops melanostictus eggs, mackerels Scomber japonicus and $S$. australasicus eggs and jack mackerel Trachurus japonicus larvae in 2 mo of their peak spawning in 1988 (during the sardine regime) and 2000 (during the anchovy regime)
24 992) and larvae $(\mathrm{n}=24$ 681), sardine eggs $(\mathrm{n}=10966)$ and larvae $(\mathrm{n}=12649)$, mackerel eggs $(n=5708)$ and larvae $(n=5440)$ and jack mackerel larvae $(n=3874)$ from all available samples. These 'positive' samples were treated equally within each combination of species and stage, regardless of egg and larval abundance. Relative frequency (\%) for each SST interval of $0.1^{\circ} \mathrm{C}$ among all SST intervals (350 intervals from 0.0 to $35.0^{\circ} \mathrm{C}$ ) was calculated for 'positive' samples of each of the 7 species/stage categories. A similar relative frequency was calculated for all available samples including positive and non-positive samples, which represent the relative sampling effort for each SST interval. Spawning temperature index, a proxy for the temperature preferred for spawning, was calculated as the ratio of relative frequency (\%) of 'positive' samples versus all samples for each SST interval for eggs and larvae of each species, based on the assumption that the occurrence of eggs or larvae indicates recent spawning. The $0.1^{\circ} \mathrm{C}$ data series of the index were then smoothed using 5-term running means. When the index value for eggs or larvae of a species was higher than 1.0 for a certain SST interval after smoothing, the temperature interval was assumed to be the preferred or selected temperature range, that is, the spawning temperature optimum. The higher index value means that spawning is more likely to occur at that temperature, and values of 1.0 or less indicate non-preference, as the relative importance of that temperature equilibrates between 'positive' samples (spawning) and all samples (sampling effort). This simple quotient rule has been used to characterize spawning habitats of small pelagic fish species (LluchBelda et al. 1991, van der Lingen et al. 2001, 2005, Twatwa et al. 2005). A non-parametric Kolmogorov-Smirnov test was applied to the cumulative frequency distributions of the raw data with the SST interval of $0.1^{\circ} \mathrm{C}$ for 'positive' samples to detect any statistical difference in the index distribution among species and between stages (Twatwa et al. 2005).

Annual total landings in weight for Japan from 1905 to 2004 were used as a qualitative proxy for biomass to describe the long-term trends of population dynamics of the targeted fish species in the west- 
ern North Pacific (Fig. 1). The total landing data were confirmed to be correlated with the biomass data of the Pacific stocks estimated through a virtual population analysis (Fisheries Agency and Fisheries Research Agency of Japan 2005) in terms of time-series trends for at least the last few decades for anchovy (Spearman's correlation coefficient test, 1978 to 2004, $\mathrm{r}_{\mathrm{S}}=0.805, \mathrm{p}<$ 0.001 ), sardine (1976 to $\left.2004, \mathrm{r}_{\mathrm{S}}=0.938, \mathrm{p}<0.001\right)$, chub mackerel (1970 to 2004, $\left.\mathrm{r}_{\mathrm{S}}=0.896, \mathrm{p}<0.001\right)$ and jack mackerel (1982 to $\left.2004, \mathrm{r}_{\mathrm{S}}=0.864, \mathrm{p}<0.001\right)$. The temperature at the modal point of the spawning temperature index corresponds to the temperature at which spawning occurred most frequently over the long term, and it distinguishes the relatively warm or cool spawning features of each species. The shape of distribution of the spawning temperature index (Fig. 3) is indicative of the extent of relative eurythermy or stenothermy, as the wider (narrower) optimum range with the lower (higher) index maximum characterizes a eurythermal (stenothermal) species. As such, the extent of relative eurythermy or stenothermy was expressed as the optimum range (the index $>1.0$ ) divided by the maximum value of the index. This ratio was compared to the coefficient of variance of annual total landings from 1905 to 2004, regarded as a substitute for the extent of population fluctuations in the long term.

\section{RESULTS}

Spawning temperature index for anchovy, sardine, mackerel and jack mackerel started to increase rapidly around $10^{\circ} \mathrm{C}$ and showed unimodal distributions (Fig. 3). However, sardine and mackerel exhibited steep modes and decreased to be nearly 0 around $26^{\circ} \mathrm{C}$, while anchovy and jack mackerel exhibited more moderate modes and did not decrease until around $27^{\circ} \mathrm{C}$. The difference in cumulative frequency distributions for 'positive' samples in relation to temperature was statistically significant among all of the species and between stages (Kolmogorov-Smirnov test, $\mathrm{p}<0.001)$, except between eggs and larvae of mackerel $(p=0.069)$. However, similarities and differences among species were observed to be evident in terms of the peak of the spawning temperature index, or the midpoint of optimum range, and the optimum range itself. Likewise, characteristics of the index patterns appeared to be similar between eggs and larvae.

The spawning temperature index (5-term running mean of $0.1^{\circ} \mathrm{C}$ data) exceeded 1.0 from 15.6 to $27.8^{\circ} \mathrm{C}$ $\left(17.6\right.$ to $28.1^{\circ} \mathrm{C}$ ) for anchovy eggs (larvae), from 13.2 to $20.2^{\circ} \mathrm{C}\left(13.8\right.$ to $20.4^{\circ} \mathrm{C}$ ) for sardine eggs (larvae), from 15.5 to $21.9^{\circ} \mathrm{C}\left(15.5\right.$ to $22.1^{\circ} \mathrm{C}$ ) for mackerel eggs (larvae) and from 17.1 to $28.0^{\circ} \mathrm{C}$ for jack mackerel larvae (Fig. 3). Sardine showed a steeply peaked spawning

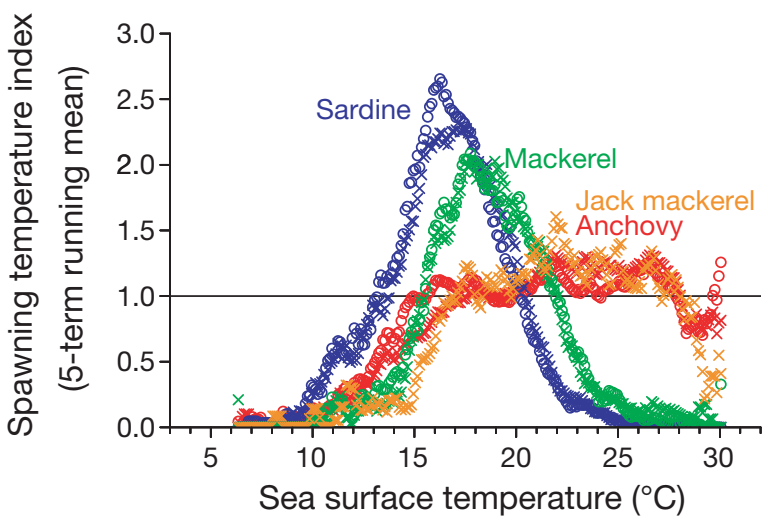

Fig. 3. Spawning temperature index for anchovy Engraulis japonicus, sardine Sardinops melanostictus, mackerels Scomber japonicus and $S$. australasicus and jack mackerel Trachurus japonicus, based on the long-term data set of egg and larval surveys off the Pacific coast of Japan from 1978 to 2004. Occurrences of eggs (circle) and larvae (cross) were analyzed separately; only larval occurrence was available for jack mackerel. The $0.1^{\circ} \mathrm{C}$ data series were smoothed by 5 -term running means; the plot for the intervals that included less than 20 samples $\left(<6.3^{\circ} \mathrm{C}\right.$ and $\left.>30.1^{\circ} \mathrm{C}\right)$ were removed. The horizontal line indicates the baseline of optima, above which temperature interval was assumed to be preferred for spawning (Lluch-Belda et al. 1991). The index patterns smoothed by 11-term running means for anchovy and sardine were also used to compare spawning temperatures between opposite sides of the North Pacific in Takasuka et al. (2008)

mode with the maximum value of index for eggs at $16.2^{\circ} \mathrm{C}$. Similarly, mackerel showed a marked peak of the index, but the index maximum at $17.7^{\circ} \mathrm{C}$ for eggs and larvae was higher than the peak temperature for sardine. In contrast, anchovy and jack mackerel exhibited very similar plateau-like patterns of the spawning temperature index. The index maxima around the midpoint of the optimum range were detected at $21.7^{\circ} \mathrm{C}$ for anchovy eggs and $21.9^{\circ} \mathrm{C}$ for jack mackerel larvae.

The optimum range divided by the index maximum was 2.6, 3.1, 6.8 and 9.8 for sardine eggs, mackerel eggs, jack mackerel larvae and anchovy eggs, respectively. The coefficient of variance for $100 \mathrm{yr}$ catches $(1.38,1.04,0.94$ and 0.65 in the above order of the 4 species) showed a negative trend with this indicator of relative eurythermy or stenothermy, although the relationship was based on 4 data points only and was not statistically significant (Spearman's correlation coefficient test, $r_{S}=-1, p=0.083$ ).

\section{DISCUSSION}

Similarities and differences in the long-term population dynamics were reflected in those of the spawning temperature patterns among the species (Figs. 1 \& 
3). The western North Pacific has historically experienced cool surface waters when the PDO index is positive and warm surface waters when it is negative (Mantua et al. 1997, Mantua \& Hare 2002, Chavez et al. 2003). The anchovy regime during the warm phase has shifted to the sardine regime during the cool phase and back twice during the 20th century. Anchovy exhibited a plateau-like spawning temperature pattern with a wider temperature optimum and a peak at ca. $22^{\circ} \mathrm{C}$. In contrast, sardine exhibited a steeply peaked pattern with a narrower temperature optimum and a marked peak at ca. $16^{\circ} \mathrm{C}$. Mackerel showed a spawning peak at ca. $18^{\circ} \mathrm{C}$, and in fact they flourished during the late 1970s between the relative abundance of anchovy (the 1960s) and sardine (the late 1980s). In contrast, jack mackerel have shown very similar population dynamics to anchovy. This close relationship was evidently reflected in the similarity in spawning temperatures of anchovy and jack mackerel. Although statistical tests discriminated the overall patterns of spawning temperature among all the target species, similarities and differences focusing on the peak, midpoint and range of spawning temperature optima would allow the target species to be categorized as follows. Anchovy and jack mackerel are warm and eurythermal species, while sardine and mackerel are cool and stenothermal species, but mackerel is less so than sardine. From such a viewpoint, the spawning temperature optima would be consistent with the timing of flourish/collapse associated with the PDO phases at multi-decadal scales. Furthermore, eurythermal/stenothermal features recorded in the spawning temperature patterns seemed to reflect the extent of population fluctuations. The lower values of the optimum range divided by the index maximum of the more stenothermal species tended toward the greater values of coefficient of variance for landings. Sardine and mackerel with more stenothermal spawning patterns indicated dramatic fluctuations relative to anchovy and jack mackerel with more eurythermal patterns.

Clearly, temperature is not the sole determinant of population dynamics. Various studies have indeed reported the effectivity of 'bottom-up' (Beaugrand et al. 2003, Platt et al. 2003, Ware \& Thomson 2005), 'topdown' (Frank et al. 2005) and 'wasp-waist' (Cury et al. 2000, Bakun 2006) controls. Density-dependent processes and interspecific interactions are potentially influential (Yatsu et al. 2005). Current intensity, transport, turbulence and salinity might also be synergistic physical factors (Twatwa et al. 2005). Further, fishing efforts may accelerate the collapse or prevent the recovery of stocks (Shelton et al. 2006). Moreover, the relative dominances of these factors may change over phases (Ciannelli et al. 2005). Various dynamic and interactive factors pose a complexity that has led to difficulty in predicting future trends.

Despite such complexity, a simple and direct mechanism might exist to regulate fish regime shifts over large temporal and spatial scales. Out-of-phase oscillations have been shown between warm and eurythermal species (i.e. anchovy and jack mackerel) and cool and stenothermal species (i.e. sardine) at different fluctuation levels. Mackerel indicated intermediate features between these 2 groups in both oscillations and spawning temperatures. As such, multi-species relationships may be reflected most directly by temperature optima rather than the other biological or taxonomic characteristics. The target species have generally different life history parameters. Anchovy mature at age $<1 \mathrm{yr}$, with a longevity of $3 \mathrm{yr}$, and spawn almost throughout the year with a peak in May to June; sardine mature at 1 to $2 \mathrm{yr}$, with a longevity of $7 \mathrm{yr}$, and spawn from November to May with a peak in February to March; mackerel mature at age 2 to $4 \mathrm{yr}$, with a longevity of $6 \mathrm{yr}$, and spawn from February to August with a peak in April to May; jack mackerel mature at 1 to $2 \mathrm{yr}$, with a longevity of $5 \mathrm{yr}$, and spawn from February to September with a peak in June to July (Fisheries Agency and Fisheries Research Agency of Japan 2005). Anchovy, sardine and jack mackerel have filter-feeding and particulate-feeding strategies, while mackerel are piscivorous. The differences in food plankton sizes and feeding organs (e.g. gill raker morphology) between anchovy and jack mackerel are greater than those between anchovy and sardine (Tanaka 2006). The same would also hold true for differences in effects of predation pressure, since preypredator interactions are largely size-dependent, and these species are sorted in descending order of size at maturity as mackerel, jack mackerel, sardine and anchovy. Nonetheless, anchovy and jack mackerel showed similar trends in their population dynamics, being out-of-phase with sardine. There should be a common factor between them; we suggest that it is species-specific temperature optima.

Fish population dynamics could be regulated more or less by direct temperature impacts, since temperature would be a primary determinant of the early growth rates at large temporal and spatial scales (Meekan et al. 2003, Baumann et al. 2006, Takasuka \& Aoki 2006). Reproductive parameters are also susceptible to temperature changes. Growth rates represent survival potential during the early life stages (Takasuka et al. 2003, 2004), and growth variability could cause over 100-fold fluctuations in survival probabilities in theory (Houde 1987, Takasuka et al. 2007a). Thus, climate-induced temperature shifts potentially trigger dramatic shifts in population abundances. Based on this assumption, the 'optimal growth temper- 
ature' hypothesis was proposed as a potential biological mechanism of anchovy and sardine alternations (Takasuka et al. 2007b). The optimal growth temperatures occurred at $22.0^{\circ} \mathrm{C}$ for anchovy larvae and at $16.2^{\circ} \mathrm{C}$ for sardine larvae in the western North Pacific. The ambient temperatures for the larvae differed between the 2 species but have actually fluctuated between these optima. The hypothesis posits that the shifts of ambient temperature between the differential optima potentially cause the shifts of anchovy and sardine regimes. The spawning temperature optima of anchovy (midpoint: $21.7^{\circ} \mathrm{C}$ ) and sardine (peak: $16.2^{\circ} \mathrm{C}$ ) showed a close agreement with their optimal growth temperatures during early life stages. This correspondence means that the present analysis on occurrence of eggs and larvae successfully detected species-specific temperature optima and that, assuming a similar correspondence, the theory is applicable to mackerel and jack mackerel. The present study extends the concept of the 'optimal growth temperature' hypothesis to the multi-species regime shifts in the western North Pacific.

The proposed theory focuses on direct temperature impacts independent of trophic interactions, in contrast to the 'bottom-up' theory. As a prevalent hypothesis of species alternations, van der Lingen et al. (2006) proposed that the shifting physical regimes lead to changes in plankton community structure, which potentially cause the shifts between a size-selective particulate-feeder (anchovy Engraulis encrasicolus) and a non-selective filter-feeder (sardine Sardinops sagax) in the Benguela ecosystem. This theory does not account for the synchrony between anchovy and jack mackerel in the western North Pacific (see above) but would be one of the possible mechanisms of anchovy and sardine alternations. On the contrary, our theoretical framework may be in agreement with the 'wasp-waist' control (Cury et al. 2000, Bakun 2006), in which a few dominant small pelagic species adversely exert effects on communities at lower and upper trophic levels. In any case, the multiple mechanisms based on direct and indirect temperature impacts and the other factors are not exclusive but synergistic in theory. Our single factor analysis did not assess the relative importance of multiple factors. However, the temperature-based concept would be a potential mechanism that at least theoretically addresses biological aspects, which have been previously hard to explain by other theories and thus would serve as an alternative/complimentary approach to unraveling the underlying mechanisms of multi-species regime shifts.

The target species can be considered as opportunistic strategists (Winemiller \& Rose 1992); thus, they might shift distributions in response to temperature shifts to some extent. Their spawning grounds exhibit inshore contraction and offshore expansion depending on the phases of population dynamics (Fig. 2). The dramatic population fluctuations in themselves indicate that the pelagic fish cannot completely adapt to environmental changes; however, their adaptive potential is unclear. Another concern is the difference in biomass levels between sardine and the other species. For example, the inshore contraction of sardine might facilitate the offshore expansion of the others, possibly exerting synergistic effects on the alternations. Future studies are needed to clarify how such temporal and spatial dynamics of spawning, their differences among species and interspecific interactions affect the multispecies regime shifts.

The present approach might have generality in further large-scale events. The relationship between Japanese anchovy Engraulis japonicus and Japanese sardine Sardinops melanostictus shows a marked contrast to the case between northern anchovy E. mordax and California sardine S. sagax in terms of temperature optima (Takasuka et al. 2008). That study compared spawning temperature optima of Japanese anchovy and sardine (as in Fig. 3) with those of northern anchovy $\left(11.5\right.$ to $\left.16.5^{\circ} \mathrm{C}\right)$ and California sardine (13 to $25^{\circ} \mathrm{C}$ ) analyzed by Lluch-Belda et al. (1991) using a uniform approach. This contrast appears to be consistent with the observation that anchovy and sardine alternations were roughly synchronous during certain phases despite the reversed temperature regimes between the opposite sides of the North Pacific (Mantua et al. 1997, Chavez et al. 2003), providing a hypothetical solution to the basin-scale phenomena (Takasuka et al. 2008).

The present multi-species comparisons extracted a simple and direct hypothesis from a complex marine ecosystem: direct temperature impacts on vital parameters independent of trophic interactions would provide a probable theoretical explanation of multi-species regime shifts of small pelagic fish in the western North Pacific, if viewed at large scales. If so, this implies the potential for fish regime shifts to be disrupted by large-scale temperature shifts, such as global warming, even without intermediary processes through food webs. At the same time, it may allow the prediction of future trends from monitoring and simulating temperature shifts, but only if fishing pressure does not affect the natural patterns.

Acknowledgements. We appreciate the efforts of participant researchers, officers, crew and operators in the egg and larval surveys and persons responsible for data accumulations in many institutes and experimental stations. In 2005 the data set was updated with the help of $M$. Ishida, H. Ebina, K. Horikoshi, T. Nagaki, T. Chiyokubo, N. Yasumi, M. Katou, H. Hashimoto, O. Funaki, T. Suzuki, K. Ninokata, H. Yamada, R. Utsumi, S. Morioka, T. Inai, S. Aono, Y. Sanada, H. Fukuda, 
K. Tanaka, M. Morinaga, M. Kajiya, M. Saito, K. Omote and S. Inaba. The PDO data were provided by S. Hare and N. Mantua. Landing data were updated from those originally prepared by A. Yatsu. The manuscript benefited from the comments of D. Robert, T. Akamine and anonymous reviewers.

\section{LITERATURE CITED}

Attrill MJ, Power M (2002) Climatic influence on a marine fish assemblage. Nature 417:275-278

Bakun A (2006) 'Wasp-waist' populations and marine ecosystem dynamics: navigating the 'predator pit' topographies. Prog Oceanogr 68:271-288

Baumann H, Gröhsler T, Kornilovs G, Makarchouk A, Feldmann V, Temming A (2006) Temperature-induced regional and temporal growth differences in Baltic young-ofthe-year sprat Sprattus sprattus. Mar Ecol Prog Ser 317: 225-236

Beaugrand G, Brander KM, Lindley JA, Souissi S, Reid PC (2003) Plankton effect on cod recruitment in the North Sea. Nature 426:661-664

Chavez FP, Ryan J, Lluch-Cota SE, Niquen CM (2003) From anchovies to sardines and back: multi-decadal change in the Pacific Ocean. Science 299:217-221

Ciannelli L, Bailey KM, Chan KS, Belgrano A, Stenseth NC (2005) Climate change causing phase transitions of walleye pollock (Theragra chalcogramma) recruitment dynamics. Proc R Soc Lond B Biol Sci 272:1735-1743

> Cury P, Bakun A, Crawford RJM, Jarre A, Quiñones RA, Shannon LJ, Verheye HM (2000) Small pelagics in upwelling systems: patterns of interaction and structural changes in 'wasp-waist' ecosystems. ICES J Mar Sci 57: 603-618

Fisheries Agency and Fisheries Research Agency of Japan (2005) Marine fisheries stock assessment and evaluation for Japanese waters (fiscal year 2005/2006). Tokyo

Frank KT, Petrie B, Choi JS, Leggett WC (2005) Trophic cascades in a formerly cod-dominated ecosystem. Science 308:1621-1623

Houde ED (1987) Fish early life dynamics and recruitment variability. Am Fish Soc Symp 2:17-29

Lluch-Belda D, Lluch-Cota DB, Hernandez-Vazquez S, SalinasZavala CA, Schwartzlose RA (1991) Sardine and anchovy spawning as related to temperature and upwelling in the California Current system. Calif Coop Ocean Fish Invest Rep 32:105-111

Mantua NJ, Hare SR (2002) The Pacific Decadal Oscillation. J Oceanogr 58:35-44

Mantua NJ, Hare SR, Zhang Y, Wallace JM, Francis RC (1997) A Pacific interdecadal climate oscillation with impacts on salmon production. Bull Am Meteorol Soc 78:1069-1079

McGowan JA, Cayan DR, Dorman LM (1998) Climate-ocean variability and ecosystem response in the Northeast Pacific. Science 281:210-217

Meekan MG, Carleton JH, McKinnon AD, Flynn K, Furnas M (2003) What determines the growth of tropical reef fish larvae in the plankton: food or temperature? Mar Ecol Prog Ser 256:193-204

Platt T, Fuentes-Yaco C, Frank KT (2003) Spring algal bloom and larval fish survival. Nature 423:398-399

Shelton PA, Sinclair AF, Chouinard GA, Mohn R, Duplisea DE

Editorial responsibility: Matthias Seaman,

Oldendorf/Luhe, Germany
(2006) Fishing under low productivity conditions is further delaying recovery of Northwest Atlantic cod (Gadus morhua). Can J Fish Aquat Sci 63:235-238

> Takasuka A, Aoki I (2006) Environmental determinants of growth rates for larval Japanese anchovy Engraulis japonicus in different waters. Fish Oceanogr 15:139-149

> Takasuka A, Aoki I, Mitani I (2003) Evidence of growthselective predation on larval Japanese anchovy Engraulis japonicus in Sagami Bay. Mar Ecol Prog Ser 252:223-238

Takasuka A, Aoki I, Mitani I (2004) Three synergistic growthrelated mechanisms in the short-term survival of larval Japanese anchovy Engraulis japonicus in Sagami Bay. Mar Ecol Prog Ser 270:217-228

Takasuka A, Aoki I, Oozeki Y (2007a) Predator-specific growth-selective predation on larval Japanese anchovy Engraulis japonicus. Mar Ecol Prog Ser 350:99-107

Takasuka A, Oozeki Y, Aoki I (2007b) Optimal growth temperature hypothesis: Why do anchovy flourish and sardine collapse or vice versa under the same ocean regime? Can J Fish Aquat Sci 64:768-776

Takasuka A, Oozeki Y, Kubota H, Lluch-Cota SE (2008) Contrasting spawning temperature optima: Why are anchovy and sardine regime shifts synchronous across the North Pacific? Prog Oceanogr 77:225-232

Tanaka H (2006) Comparative study of the feeding ecology of small pelagic fish with a focus on Japanese anchovy Engraulis japonicus. PhD thesis, University of Tokyo

Twatwa NM, van der Lingen CD, Drapeau L, Moloney CL, Field JG (2005) Characterising and comparing the spawning habitats of anchovy Engraulis encrasicolus and sardine Sardinops sagax in the southern Benguela upwelling ecosystem. Afr J Mar Sci 27:487-499

van der Lingen $C D$, Hutchings L, Merkle D, van der Westhuizen JJ, Nelson J (2001) Comparative spawning habitats of anchovy Engraulis capensis and sardine Sardinops sagax in the Southern Benguela upwelling ecosystem. In: Kruse GH, Bez N, Booth T, Dorn M, Hills S, Lipcius RN, Pelletier D, Roy C, Smith SJ, Witherell D (eds) Spatial processes and management of marine populations. University of Alaska Sea Grant, AK-SG-01-02, Fairbanks, p 185-209

van der Lingen CD, Castro L, Drapeau L, Checkley D Jr (eds) (2005) Report of a GLOBEC-SPACC workshop on characterizing and comparing the spawning habitats of small pelagic fish. GLOBEC Rep 21, Plymouth

van der Lingen CD, Hutchings L, Field JG (2006) Comparative trophodynamics of anchovy (Engraulis encrasicolus) and sardine (Sardinops sagax) in the southern Benguela: are species alternations between small pelagic fish trophodynamically mediated? Afr J Mar Sci 28:465-477

Ware DM, Thomson RE (2005) Bottom-up ecosystem trophic dynamics determine fish production in the Northeast Pacific. Science 308:1280-1284

Winemiller KO, Rose KA (1992) Patterns of life history diversification in North American fishes: implications for population regulation. Can J Fish Aquat Sci 49:2196-2218

Yatsu A, Watanabe T, Ishida M, Sugisaki H, Jacobson LD (2005) Environmental effects on recruitment and productivity of Japanese sardine Sardinops melanostictus and chub mackerel Scomber japonicus with recommendations for management. Fish Oceanogr 14:263-278

Submitted: August 21, 2006; Accepted: January 15, 2008 Proofs received from author(s): May 13, 2008 